\title{
Inflammatory myofibroblastic tumours: where are we now?
}

\author{
B C Gleason, J L Hornick
}

Department of Pathology, Brigham and Women's Hospital and Harvard Medical School, Boston, MA, USA

Correspondence to:

Dr Jason L Hornick, Department of Pathology, Brigham and Women's Hospital, 75 Francis Street, Boston, MA 02115, USA; jhornick@partners.org

Accepted 27 September 2007 Published Online First 15 October 2007

\begin{abstract}
Inflammatory pseudotumour is a generic term applied to a variety of neoplastic and non-neoplastic entities that share a common histological appearance, namely a cytologically bland spindle cell proliferation with a prominent, usually chronic inflammatory infiltrate. Over the last two decades, inflammatory myofibroblastic tumour (IMT) has emerged from within the broad category of inflammatory pseudotumour, with distinctive clinical, pathological and molecular features. IMT shows a predilection for the visceral soft tissues of children and adolescents and has a tendency for local recurrence, but only a small risk of distant metastasis. Characteristic histological patterns include the fasciitis-like, compact spindle cell and hypocellular fibrous patterns, which are often seen in combination within the same tumour. Chromosomal translocations leading to activation of the ALK tyrosine kinase can be detected in approximately 50\% of IMTs, particularly those arising in young patients. This review will examine the clinical, pathological, and molecular genetic features of IMT and discuss an approach to diagnosis and differential diagnosis.
\end{abstract}

The term "inflammatory pseudotumour" has been used to describe a wide range of reactive and neoplastic lesions, including inflammatory myofibroblastic tumour (IMT), pseudosarcomatous myofibroblastic proliferations of the genitourinary (GU) tract, infectious and reparative processes, and inflammatory pseudotumours of lymph node, spleen and orbit. Over the last two decades, IMT has emerged as a distinct entity with characteristic clinical, pathological and molecular features. However, confusion remains regarding the distinction of these tumours from other lesions in the "inflammatory pseudotumour" family, as well as from non-neoplastic fibrosclerosing processes and malignant neoplasms with a prominent inflammatory infiltrate. This review will examine the clinicopathological and molecular features of IMT and discuss its differential diagnosis, with emphasis on other entities included under the umbrella of inflammatory pseudotumour.

\section{HISTORY}

Inflammatory pseudotumour was first described in the lung, where it was considered a reparative postinflammatory condition rather than a neoplastic process. ${ }^{12}$ Histologically similar lesions were subsequently reported at extrapulmonary sites, and distinctive clinical features, including a predilection for children and young adults and associated systemic symptoms in a minority of patients, were recognised..$^{3-8}$ These tumours were widely considered benign and likely non-neoplastic until the early 1990s when Meis and Enzinger published a series of 38 cases, primarily intraabdominal and retroperitoneal tumours in children and adolescents, which they termed "inflammatory fibrosarcoma" based on follow-up data showing a significant rate of aggressive behaviour. ${ }^{9}$ Among the 27 patients with clinical follow-up in this series, 10 (37\%) had local recurrences, 3 (11\%) developed metastases, and $5(19 \%)$ died from disease. $^{9}$ In 1995, Coffin et al reported 84 cases of extrapulmonary IMT, which overlapped clinically and histologically with "inflammatory fibrosarcoma," although the recurrence rate was somewhat lower $(25 \%)$ and no metastases occurred. ${ }^{10}$ The identification of recurrent clonal rearrangements involving chromosome $2 \mathrm{p}$ over the next several years provided additional support that IMT was a distinct neoplasm; "inflammatory fibrosarcoma" is now considered indistinguishable from, and within the morphological spectrum of, IMT.

\section{CLINICAL FEATURES}

IMTs have a predilection for children and adolescents, although they may arise as late as the eighth decade of life. ${ }^{911} 12$ The most common anatomical locations are the abdominopelvic region, lung, and retroperitoneum, ${ }^{10}$ but virtually any site may be involved, including the somatic soft tissues, bone, larynx, uterus and central nervous system. ${ }^{13-17}$ Accurate data regarding the incidence and anatomical distribution of IMT are difficult to obtain due to the use of the terms "inflammatory pseudotumour" and "IMT" interchangeably in the literature; however, one recent review of 275 "inflammatory pseudotumours" in children reported that approximately one-third of cases were pulmonary and two-thirds were extrapulmonary. ${ }^{18}$

Patients generally present with a mass or nonspecific symptoms, including vague abdominal pain or gastrointestinal complaints for intraabdominal lesions, and cough, chest pain, or, less often, haemoptysis for pulmonary tumours. ${ }^{10} 1920$ A constitutional syndrome consisting of fever, weight loss and malaise is seen in $15-30 \%$ of patients, and laboratory evaluation may reveal microcytic anaemia, a raised erythrocyte sedimentation rate, thrombocytosis, and/or polyclonal hypergammaglobulinaemia. ${ }^{9}{ }^{10}$ In some cases, the mass may be found only after an extensive workup for fever of unknown origin or growth failure. ${ }^{5}{ }^{21}$ The systemic manifestations resolve following surgical excision, and tumour recurrence may be heralded by a return of clinical and laboratory abnormalities. ${ }^{10} 1921$ A similar clinical presentation may be seen in the plasma cell variant of 


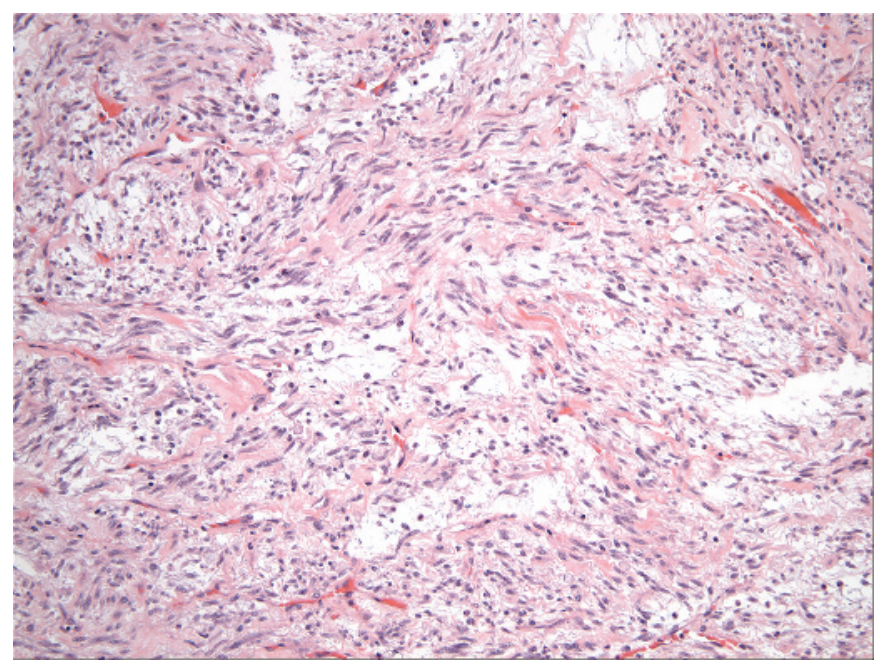

Figure 1 A gastric inflammatory myofibroblastic tumour with a fasciitis-like appearance. Note the loosely arranged spindle cells and the prominent myxoid stroma.

Castleman disease, in which overproduction of interleukin 6 (IL-6) is thought to be the underlying cause of the systemic complaints. ${ }^{22}$ Two patients with IMT were reported to have raised serum levels of IL-6 that returned to normal postoperatively as their systemic symptoms resolved, ${ }^{23}{ }^{24}$ and several authors have demonstrated production of IL- 6 mRNA and protein by tumour cells, supporting a possible analogous mechanism in IMT. ${ }^{23-25}$

\section{PATHOLOGICAL FEATURES}

Grossly, IMTs may be firm, fleshy, or gelatinous, with a white or tan cut surface. Calcification, haemorrhage and necrosis are identified in a minority of cases. ${ }^{9}{ }^{10}$ Tumours range from $1 \mathrm{~cm}$ to $>20 \mathrm{~cm}$ in greatest dimension, with a mean size of $6 \mathrm{~cm} .{ }^{9}{ }^{10} \mathrm{~A}$ subset of IMTs, particularly those in the abdomen or retroperitoneum, present as multiple discrete masses in the same anatomical region. $^{79} 10$

Histologically, IMTs are characterised by a variably cellular spindle cell proliferation in a myxoid to collagenous stroma with a prominent inflammatory infiltrate composed primarily of plasma cells and lymphocytes, with occasional admixed eosinophils and neutrophils. Coffin et al described three basic histological patterns, which are often seen in combination within the same tumour: a myxoid/vascular pattern, a compact spindle cell pattern, and a hypocellular fibrous (fibromatosislike) pattern. ${ }^{10}$ The myxoid/vascular pattern has a fasciitis-like appearance, with loosely arranged plump spindle cells in an oedematous or myxoid stroma and a prominent vasculature (fig 1). The inflammatory infiltrate in these areas often contains more neutrophils and eosinophils and fewer plasma cells than in the other two patterns. The compact spindle cell pattern is characterised by a cellular proliferation of spindle cells with a fascicular or storiform architecture in a collagenous stroma (fig 2). These foci typically show numerous plasma cells and lymphocytes intimately admixed with the spindle cells, but discrete lymphoid follicles and aggregates of plasma cells are also common. The fibromatosis-like pattern is relatively hypocellular, with elongated rather than plump spindle cells in a densely collagenous background containing scattered lymphocytes, plasma cells and eosinophils (fig 3). Focal dystrophic calcification and even metaplastic ossification can be seen in hyalinised areas. $^{10}{ }^{26}$ Foamy histiocytes are prominent in a minority of IMTs. ${ }^{15} 19$

The spindle cells of IMT are typically uniform and predominantly myofibroblastic in appearance, with palely eosinophilic cytoplasm, plump ovoid to tapering vesicular nuclei and one or two small nucleoli (fig 4). Mild nuclear pleomorphism may be seen, but hyperchromasia is absent. Approximately one half of cases contain scattered "ganglion-like" cells (fig 5): larger polygonal cells with abundant amphophilic to eosinophilic cytoplasm, large vesicular nuclei and prominent nucleoli, similar to those seen in proliferative fasciitis. ${ }^{927}$ Mitotic activity is generally low (0-2 mitoses per $10 \mathrm{HPF})$, and atypical mitoses are rare. ${ }^{10} 152728$ Necrosis and vascular invasion have been reported in typical IMTs but are very infrequent. ${ }^{10}{ }^{29}$ Rarely, IMTs may undergo histological evolution to a morphologically higher grade lesion (fig 6) with increased cellularity, marked nuclear atypia, frequent mitoses, atypical mitotic figures, and/ or necrosis. ${ }^{10} 202831$ The cytological features of the morphologically higher grade tumours are variable, including hypercellular spindle cell, epithelioid/histiocytoid, or round cell morphology. ${ }^{10} 2831$

By ultrastructural analysis, IMTs are composed predominantly of myofibroblasts with a smaller fibroblastic component ${ }^{10} 19{ }^{32}$; the ganglion-like cells show features of fibroblasts. ${ }^{33}$ As expected given their myofibroblastic differentiation, IMTs are positive for smooth muscle actin in $80-90 \%$ of cases and express desmin and calponin in 60-70\%, although reactivity for these markers is often focal. ${ }^{10} 153033$ Approximately one-third of tumours show focal keratin reactivity, ${ }^{10}{ }^{34}$ which is not unexpected given that myofibroblasts, similar to smooth muscle cells, may be keratin positive. ${ }^{35}{ }^{36}$ The plasma cell infiltrate is polyclonal. ${ }^{15} 19$

Due to the prominent inflammatory infiltrate and associated systemic symptoms in a minority of patients with IMT, a viral aetiology has been proposed, but the evidence in this regard is unconvincing. A small subset of so-called inflammatory pseudotumours of lymph node, liver and spleen contain detectable Epstein-Barr virus (EBV) ${ }^{37-39}$; however, it is likely that most if not all of these cases do not represent true IMTs (see below). The presence of EBV in classic IMTs of other anatomical sites is rare. ${ }^{10} 33$ 40-42 One group identified human herpesvirus-8 (HHV-8) DNA in both pulmonary and extrapulmonary IMT, but expression of HHV-8-associated antigens was not investigated, ${ }^{25} 43$ and other authors have not found evidence for HHV-8 infection in IMT. ${ }^{40}{ }^{41}$

\section{MOLECULAR FEATURES}

Rearrangements involving the $A L K$ (anaplastic lymphoma kinase) locus on chromosome 2 p23 have been documented in both pulmonary and extrapulmonary IMTs, providing further support for the neoplastic nature of these lesions and their distinction from other "inflammatory pseudotumours". ${ }^{44} 45$ The ALK gene encodes a receptor tyrosine kinase that is only expressed in neural tissue under normal conditions. ${ }^{46}$ Clonal abnormalities of $A L K$ were first described in anaplastic large cell lymphoma (ALCL), in which $50-60 \%$ of cases contain a translocation of the $A L K$ gene leading to constitutive tyrosine kinase activation. ${ }^{47}$ Approximately $50 \%$ of IMTs also show $A L K$ rearrangements by $\mathrm{FISH}_{,}{ }^{44}$ and several $A L K$ fusion partners have been identified, including TPM3 at 1p23, TPM4 at 19p13, ATIC at $2 \mathrm{q} 35, C L T C$ at $17 \mathrm{q} 23$, CARS at $11 \mathrm{p} 15$, RANBP2 at $2 \mathrm{q} 13$ and SEC31L1 at 4q21. ${ }^{48-54}$ The most common fusion protein in ALCL (NPM-ALK) has not been identified in IMT, but the TPM3ALK, ATIC-ALK and CLTC-ALK fusion proteins have been 

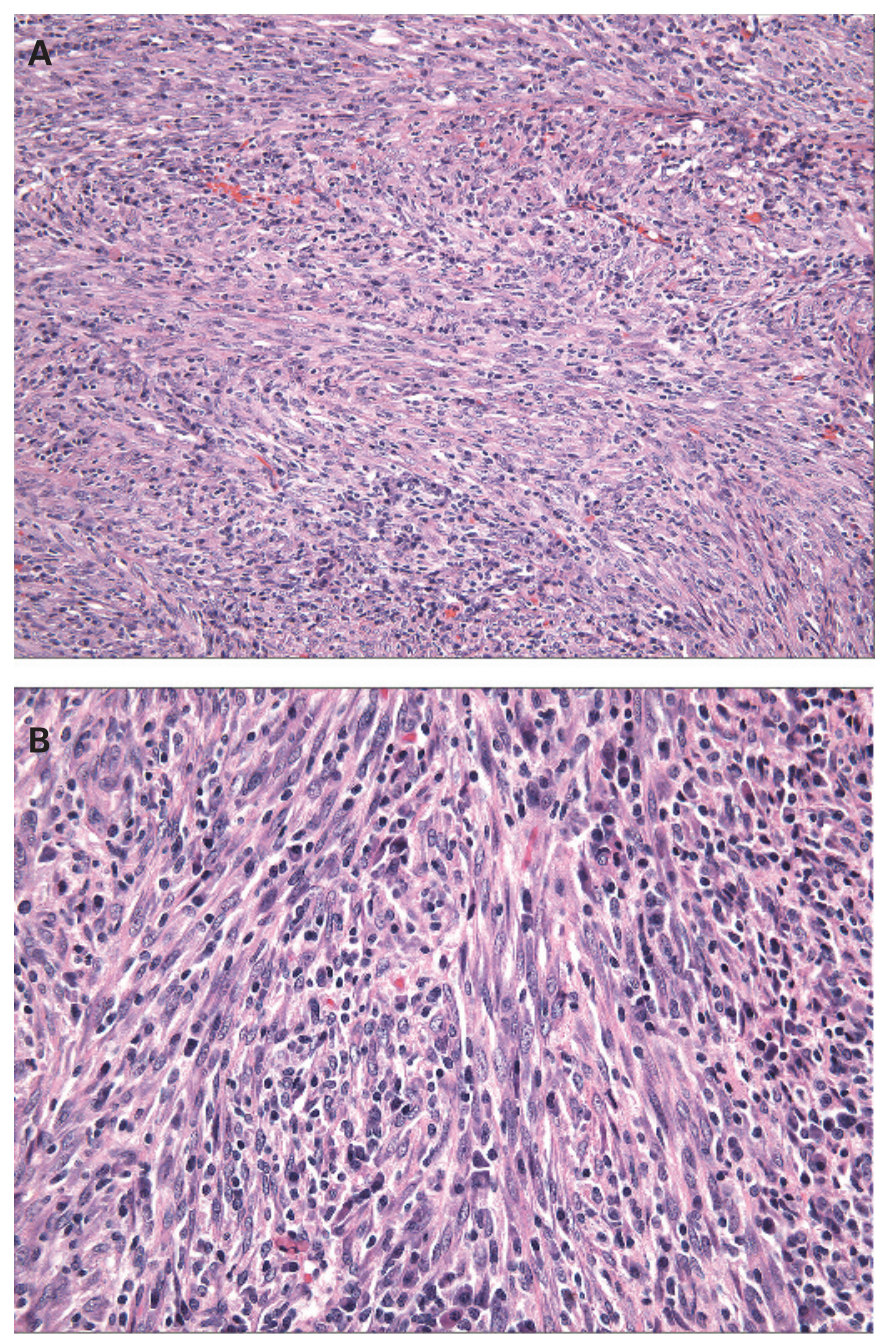

Figure 2 A cellular inflammatory myofibroblastic tumour of the lung showing (A) a fascicular architecture and (B) numerous admixed plasma cells and lymphocytes.

reported in both neoplasms, and thus represent rare examples of translocation-derived chimeric tyrosine kinases driving both mesenchymal and lymphoid neoplasms.

By immunohistochemistry, approximately $50 \%$ of IMTs are positive for ALK, with reactivity in several large series ranging from $36 \%$ to $71 \%$ (fig 7). Similar to ALCL, ALK expression in IMT is more common in younger patients, but is not restricted to this population. ${ }^{1145060}$ ALK expression in IMT reliably predicts the presence of an $A L K$ gene rearrangement (which can be detected by FISH or RT-PCR), ${ }^{11}{ }^{42} 44$ and the pattern of ALK immunostaining may correlate with the specific gene fusion, ${ }^{11}$ although this has yet to be validated in large series of ALKpositive cases. Localisation of ALK within the cell appears to be determined by its fusion partner, leading to diffuse cytoplasmic staining for ALK with the TPM3, TPM4, CARS, ATIC and SEC31L1 fusion partners, all of which are cytoplasmic proteins $^{11515254}$; nuclear membrane staining with the RANBP2 fusion partner, a nuclear pore protein ${ }^{1153}$; and granular cytoplasmic staining with the CLTC fusion partner, a main structural protein of coated vesicles. ${ }^{119}$ Although current data are too limited to draw conclusions regarding a possible relationship between gene fusion type and prognosis, both reported cases with the RANBP2-ALK fusion showed round cell
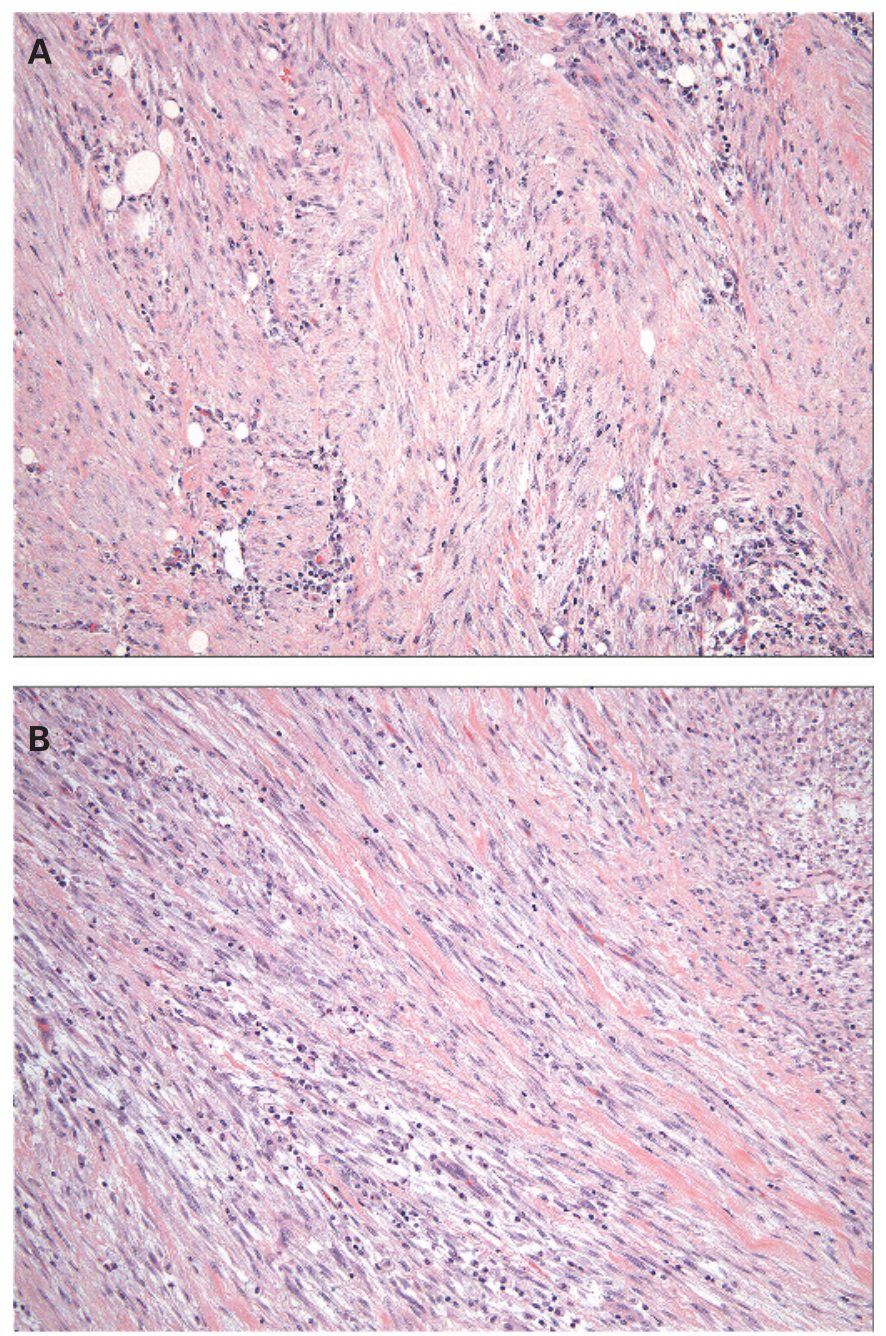

Figure 3 A hypocellular abdominal inflammatory myofibroblastic tumour (A) resembling desmoid fibromatosis. Note the hyalinised stroma and scattered plasma cells. (B) A more cellular area composed of plump myofibroblasts.

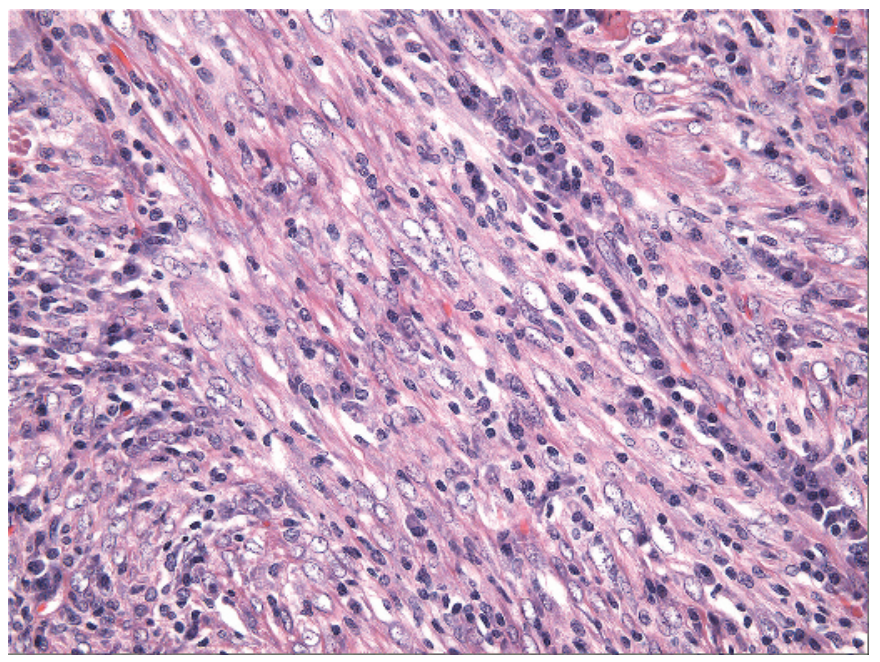

Figure 4 Typical cytomorphology in an inflammatory myofibroblastic tumour. The uniform spindle cells contain ovoid nuclei with vesicular chromatin and palely eosinophilic cytoplasm. Note the prominent plasma cells. 


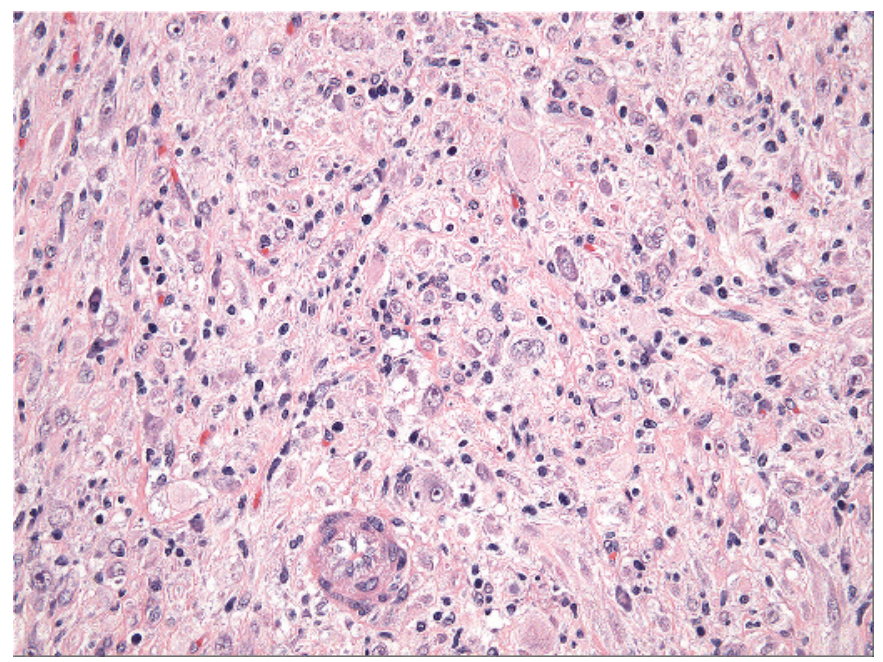

Figure 5 "Ganglion-like" cells in a colonic inflammatory

myofibroblastic tumour: large polygonal cells with abundant amphophilic cytoplasm, vesicular nuclei, and prominent nucleoli.

transformation, raising the possibility that this subset may be clinically more aggressive. ${ }^{11}{ }^{53}$

Most other myofibroblastic and fibroblastic tumours, including desmoid fibromatosis, nodular fasciitis, calcifying fibrous tumour, myofibromatosis, and infantile fibrosarcoma, are negative for ALK. ${ }^{116162}$ ALK expression has been reported in a subset of malignant peripheral nerve sheath tumours, rhabdomyosarcomas, Ewing sarcomas, leiomyosarcomas, extraskeletal myxoid chondrosarcomas, and benign and malignant adipocytic neoplasms, ${ }^{116163}$ but with the exception of leiomyosarcoma, these tumours generally do not enter the histological differential diagnosis of IMT. The molecular mechanisms responsible for ALK expression in non-IMT mesenchymal tumours are uncertain; most cases lack ALK rearrangements by RT-PCR or FISH and express the full-length ALK transcript rather than the truncated or chimeric form seen in IMTs. ${ }^{61}$

\section{PROGNOSIS}

IMTs are classified as tumours of intermediate biological potential by the most recent World Health Organization classification, due to a tendency for local recurrence and a small risk of distant metastasis. ${ }^{34}$ The recurrence rate varies by anatomical site, from $<2 \%$ for tumours confined to the lung ${ }^{18} 64$ to $25 \%$ for extrapulmonary lesions. ${ }^{10}$ Recurrences are particularly common among multinodular intra-abdominal tumours and those in delicate anatomical locations such as the larynx or trachea, likely reflecting the difficulty of complete surgical resection. In contrast, several recent studies have reported that recurrence is very infrequent following complete excision of a solitary lesion. ${ }^{64-67}$

Distant metastasis of IMT is rare, occurring in $<5 \%$ of cases. ${ }^{34}$ Of the 21 metastasising IMTs in the literature, the primary tumours affected patients over a broad age range (17 months to 79 years) and arose in a variety of anatomical sites, including 7 in the lung, 6 in the abdomen/mesentery, 3 in the retroperitoneum, and 1 each in the mediastinum, liver, iliac bone, neck, and forearm. ${ }^{912} 2831325168-75$ The most common sites of metastasis are lung and brain, followed by liver and bone. Metastatic disease is usually identified at presentation or within a year of diagnosis, but occasional patients develop metastases as many as 9 years following excision. ${ }^{74}$
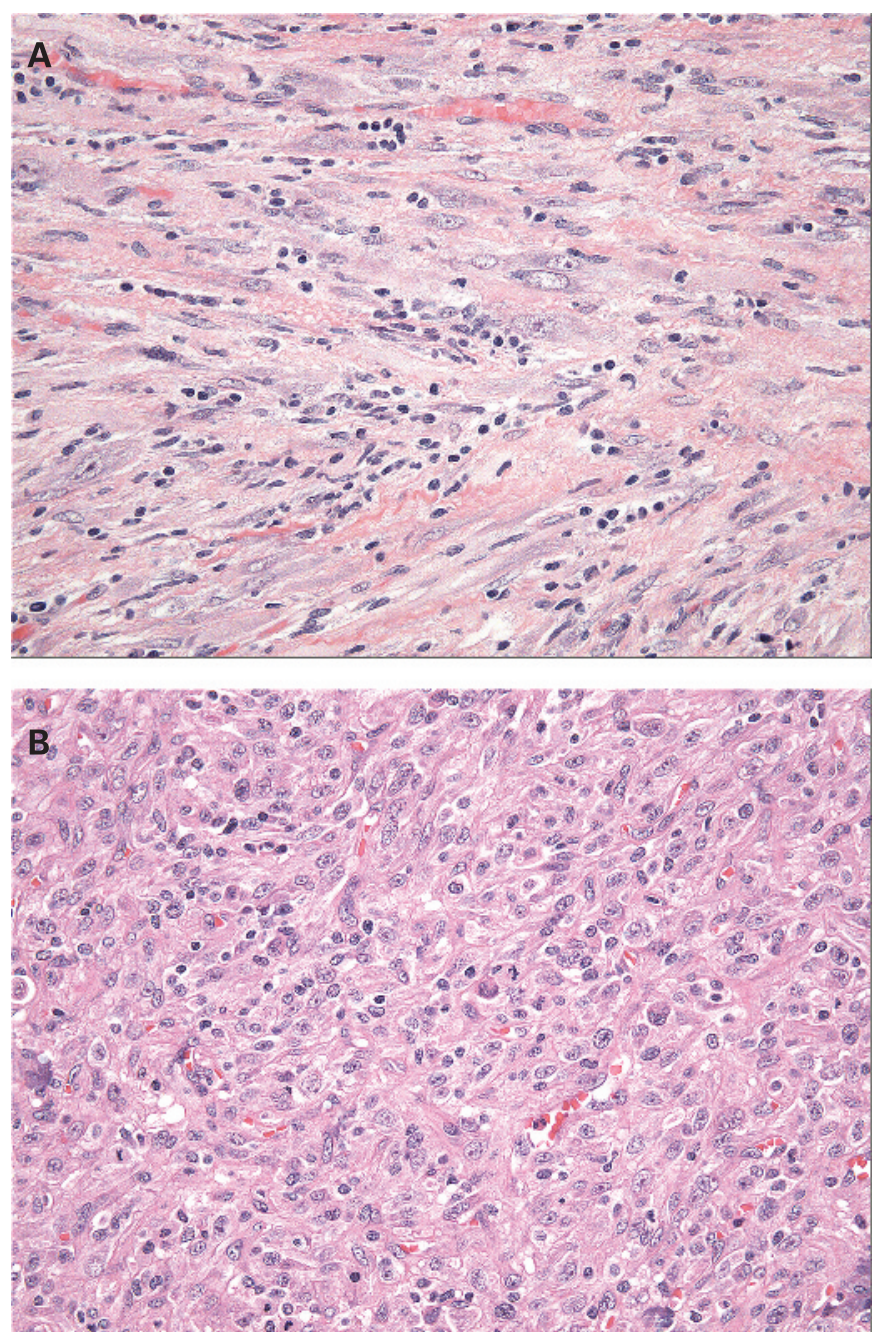

Figure 6 Recurrent abdominal inflammatory myofibroblastic tumour showing histological progression. (A) The primary tumour was composed of plump spindled myofibroblasts in a collagenous stroma with prominent lymphocytes. (B) The recurrence was a highly cellular tumour composed of histiocytoid cells with mild nuclear atypia and a high mitotic rate.

Several studies have attempted to identify histological predictors of aggressive behaviour in IMT without much success. Tumour size, cellularity, mitotic activity and the presence of necrosis do not appear to correlate with outcome. ${ }^{27} 28{ }^{30}$ One study suggested that the presence of nuclear atypia and ganglion-like cells might indicate more aggressive behaviour, but these features were also seen in over half of the clinically benign IMTs, limiting their prognostic utility. ${ }^{27}$ Furthermore, in a recent study of atypical and/or clinically aggressive IMTs, half of the metastasising cases showed no atypical features. ${ }^{28}$ In contrast to ALCL, in which ALK-positive tumours pursue a less aggressive clinical course, there is no clearcut relationship between ALK expression and prognosis in IMT. $28{ }^{30} 44{ }^{75}$ Recent studies suggest that ALK-positive tumours have a very low risk of metastasis (if any), but ALK reactivity does not appear to correlate with recurrence. ${ }^{28} 4475$ The role of p53 reactivity in predicting behaviour of IMTs is uncertain, as the frequency of p53 immunoexpression has ranged from $<10 \%$ to $80 \%$ in various studies, and some investigators have shown a correlation between p53 positivity and aggressive behaviour, while others have not. ${ }^{28}{ }^{30}$ DNA aneuploidy as determined by 


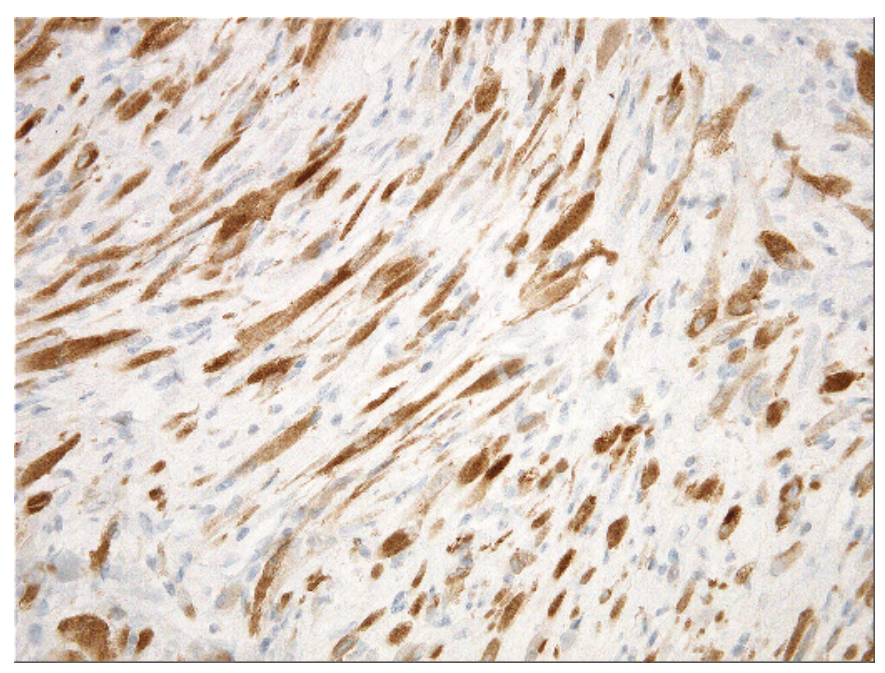

Figure 7 By immunohistochemistry, 50\% of inflammatory myofibroblastic tumours show expression of ALK, which correlates with $A L K$ gene rearrangement. ALK expression is inflammatory myofibroblastic tumours is most common in paediatric and young adult patients.

flow cytometry may be associated with an increased risk of recurrence, ${ }^{27} 3276$ but this technique is not widely available.

\section{DIAGNOSTIC APPROACH AND DIFFERENTIAL DIAGNOSIS}

Table 1 lists several key points to consider when confronted with a spindle cell lesion containing a prominent inflammatory infiltrate. These points should be considered general (not invariant) guidelines.

In our experience, IMTs are more commonly overdiagnosed than underdiagnosed. Attention to the clinical context will often prevent this error-in particular, one should be wary of making the diagnosis of IMT in a middle-aged or elderly patient. The anatomical site also provides clues, since these tumours have a strong predilection for visceral organs and the deep soft tissues of the abdomen, pelvis, and retroperitoneum. IMT should be considered a diagnosis of exclusion in the skin and superficial somatic soft tissues, lymph node, spleen or bladder, where close histological mimics are more common (see discussion below). The histological differential diagnosis of IMT depends in part on the dominant pattern-myxoid/ vascular, compact spindle cell or fibromatosis-like. In general, immunohistochemistry does not play a major role in confirming the diagnosis, due to the variable expression and lack of specificity of myofibroblastic markers. ALK positivity is helpful if present, but its absence does not exclude the diagnosis of IMT, particularly in adults. We will first consider the specific differential diagnosis of IMT based on histological pattern, and then discuss criteria for the diagnosis at several specific anatomical sites, focusing on those in which the distinction between "inflammatory pseudotumour" and IMT is poorly defined.

The compact spindle cell pattern of IMT is particularly difficult to distinguish from a variety of histological mimics. Occasional spindle cell sarcomas, spindle cell melanomas, and sarcomatoid carcinomas contain a marked inflammatory infiltrate, and may show only mild cytological atypia. ${ }^{77-79}$ However, plasma cells are generally not a prominent component of the inflammatory infiltrate in these other tumour types, and most examples show at least focally prominent nuclear hyperchromasia, atypical mitoses, necrosis or vascular invasion, all of which are very unusual in IMT. Dedifferentiated liposarcoma can be particularly challenging, especially on a biopsy specimen, as morphologically low grade lesions are often remarkably bland, ${ }^{80-82}$ and immunohistochemistry for MDM2, a sensitive marker of dedifferentiated liposarcoma, ${ }^{83}$ is not helpful in this distinction, given that a significant proportion of IMTs show nuclear MDM2 expression. ${ }^{28}{ }^{30}$ However, dedifferentiated liposarcoma usually presents in an older age group than IMT, and adequate sampling of the mass and adjacent soft tissue will usually reveal a higher grade component and/or areas of welldifferentiated liposarcoma. Due to their predominance among mesenchymal tumours of the GI tract and mesentery, gastrointestinal stromal tumours (GISTs) may be considered in the differential diagnosis of cellular IMTs in the abdomen. However, the palely eosinophilic, syncytial cytoplasm and cytological uniformity of GISTs contrast with the plump myofibroblasts, scattered ganglion-like cells and collagenous background seen in IMT. Furthermore, although an inflammatory infiltrate may be seen in GISTs, it is generally patchy, and plasma cells are infrequent. Immunohistochemistry is helpful in this differential diagnosis, as IMTs are consistently negative for c-kit. ${ }^{11}{ }^{84}$ Other entities to consider in the differential diagnosis of cellular IMTs are dendritic cell neoplasms, which characteristically show an evenly distributed chronic inflammatory infiltrate admixed with the spindle cell component. ${ }^{85}$ Follicular dendritic cell (FDC) and interdigitating dendritic cell (IDC) sarcomas are readily distinguished from IMT by immunohistochemistry, as the former express CD21 and/or CD35, and the latter are uniformly positive for S100 protein. Fibroblastic reticulum cell (FBRC) tumours are exceptionally rare with only few reports in the literature, most of which have arisen in lymph nodes, where IMT is very uncommon. ${ }^{85} 86$ FBRC tumours may be histologically indistinguishable from IMT and have a similar immunoprofile, including variable expression of SMA, desmin and keratin. Indeed, Rosai et al have recently proposed that IMTs show fibroblastic reticulum cell, rather than myofibroblastic, differentiation, ${ }^{87}$ but this hypothesis remains speculative. Finally, inflammatory leiomyosarcoma, although a

Table 1 Clinical and pathological features to consider before diagnosing inflammatory myofibroblastic tumour (IMT)

\begin{tabular}{ll}
\hline Features that favour IMT & Features that argue against IMT \\
\hline $\begin{array}{l}\text { Child or young adult } \\
\begin{array}{l}\text { Mass in lung or soft tissue of abdomen, pelvis, or } \\
\text { retroperitoneum }\end{array}\end{array}$ & $\begin{array}{l}\text { Middle-aged or older adult } \\
\text { Mass in skin or subcutis, lymph node, spleen, or bladder }\end{array}$ \\
$\begin{array}{l}\text { Diffuse inflammatory infiltrate with prominent plasma cells } \\
\text { Mild nuclear atypia including scattered ganglion-like cells }\end{array}$ & $\begin{array}{l}\text { Patchy, predominantly lymphocytic inflammatory infiltrate } \\
\text { Low mitotic rate without atypical forms }\end{array}$ \\
$\begin{array}{l}\text { ALK positivity by immunohistochemistry or } A L K \text { gene } \\
\text { rearrangement }\end{array}$ & $\begin{array}{l}\text { Atypical mitoses } \\
\text { Necrosis }\end{array}$ \\
\hline
\end{tabular}


rare histological variant, deserves mention, as it shares several features with IMT, including a predilection for young adults, a mixed storiform and fascicular spindle cell architecture, and a prominent inflammatory infiltrate, often with numerous foamy histiocytes. $^{88}$ However, focal areas with typical histological features of leiomyosarcoma-namely, fascicles of spindle cells with cigar-shaped nuclei and brightly eosinophilic cytoplasmcan usually be identified.

Fibromatosis-like or hypocellular fibrous IMTs may show histological overlap with desmoid fibromatosis or calcifying fibrous tumour, depending on the degree of stromal hyalinisation. Desmoid fibromatosis, particularly if located in the mesentery, not infrequently shows focally fasciitis-like features, enhancing the histological resemblance to IMT. In classic areas, however, the spindle cells of fibromatosis are arranged in characteristic long fascicles, in contrast to the short fascicular or storiform patterns of IMT, and although a lymphocytic infiltrate may be present in desmoid tumours, plasma cells are infrequent. Furthermore, these lesions generally show aberrant nuclear positivity for $\beta$-catenin. ${ }^{89}$ Calcifying fibrous tumour is a rare benign neoplasm with a predilection for young patients and a wide anatomical distribution. Some authors have proposed that this lesion represents a late stage of IMT, ${ }^{90}$ while others have found no convincing link between the two entities. ${ }^{62} 91$ Histologically, calcifying fibrous tumours are uniformly hypocellular, in contrast to the variable cellularity of IMTs, and they usually contain scattered psammomatous or dystrophic calcifications.

The principal entity in the differential diagnosis of IMTs dominated by the myxoid/vascular pattern is nodular fasciitis. Clinical information is often helpful in this differential, as nodular fasciitis usually appears rapidly over a few weeks to months, is rarely larger than a few centimetres in size, and typically arises in subcutaneous tissue or skeletal muscle, where IMT is very uncommon. Histologically, IMTs contain a much more prominent inflammatory infiltrate than nodular fasciitis and usually show collagenous storiform or fascicular areas, which are not seen in the latter. Occasionally, reactive processes dominated by granulation tissue may mimic IMTs with the myxoid/vascular pattern. In the absence of a supportive clinical history, histological clues to a reactive/post-traumatic process include an organised vascular pattern and fat necrosis in the adjacent soft tissue. Fasciitis-like IMTs arising in the GU tract should be distinguished from pseudosarcomatous myofibroblastic proliferations (see below).

\section{Inflammatory pseudotumour versus IMT}

As discussed above, IMT was formerly buried within the broad category of non-neoplastic fibroinflammatory and neoplastic lesions referred to as inflammatory pseudotumour. The use of these terms synonymously in the literature has led to confusion regarding the true incidence and behaviour of, and the diagnostic criteria for, IMT at a variety of sites, particularly the lung, liver, spleen, lymph node, and bladder.

Pulmonary inflammatory pseudotumour (also often referred to as plasma cell granuloma) encompasses a variety of entities, including IMT and post-infectious/reparative processes, of which the latter are likely more common. ${ }^{20} 9293$ Twenty to $30 \%$ of patients with pulmonary inflammatory pseudotumour report a history of lower respiratory tract infection, while others have a history of pulmonary infarcts or prior radiation therapy. ${ }^{19} 209294$ Organising pneumonia is frequently identified within or at the periphery of these lesions, ${ }^{20}{ }^{92}$ and many cases show features not seen in IMT, such as granulomatous inflammation, abscess formation, and numerous lymphoid follicles with germinal centres. ${ }^{92}$ A recent study reported increased IgG4-positive plasma cells and obliterative phlebitis in a series of plasma cell-rich pulmonary inflammatory pseudotumours, suggesting that some cases may have an autoimmune aetiology and form part of the spectrum of the recently recognised "systemic IgG4-related sclerosing disease". ${ }^{95-97}$ The broader age distribution and lower recurrence rate for pulmonary IMT as compared to extrapulmonary tumours ${ }^{18} 6498$ may be due in part to the inclusion of non-neoplastic processes in prior studies. That said, the lung remains a common site for true IMT, and, conversely, IMT is one of the most common primary pulmonary neoplasms in children. ${ }^{94} 99$

Similar to those in the lung, hepatic "inflammatory pseudotumours" represent a diverse group of lesions with infectious, autoimmune and neoplastic aetiologies, the latter including inflammatory pseudotumour-like FDC sarcoma and IMT. A bacterial or fungal cause has been identified in several cases of hepatic inflammatory pseudotumour, and in some reports, the masses resolved following antibiotic therapy. ${ }^{100-102}$ Prior reports of EBV in hepatic inflammatory pseudotumours are now believed primarily to represent inflammatory pseudotumourlike FDC sarcomas. ${ }^{103-105}$ This distinctive variant of FDC sarcoma characteristically arises in the liver and spleen of female patients, frequently presents with systemic symptoms, and shows a consistent association with EBV. ${ }^{105}$ Histologically, inflammatory pseudotumour-like FDC sarcomas are composed of spindle cells with vesicular nuclei and palely eosinophilic cytoplasm and show a marked lymphoplasmacytic infiltrate, thus closely mimicking IMT. Immunohistochemistry is often required to distinguish between these two neoplasms: the spindle cells of inflammatory pseudotumour-like FDC sarcoma express at least one of the FDC markers (CD21, CD23, and CD35), are negative for ALK, and are consistently positive for EBER (EBV-encoded mRNA). ${ }^{105}$ Finally, recent studies suggest that hepatic inflammatory pseudotumours dominated by lymphoplasmacytic inflammation with a minimal myofibroblastic component may be a manifestation of the systemic IgG4-related sclerosing disease (see above). ${ }^{106} 107$ Similar to the pancreatic lesions associated with this disorder ("autoimmune" or lymphoplasmacytic sclerosing pancreatitis), the "lymphoplasmacytic type" of hepatic inflammatory pseudotumour consistently shows increased IgG4-positive plasma cells, obliterative phlebitis, and periductal inflammation with concentric fibrosis, whereas these findings are less common or absent in the "fibrohistiocytic type" of hepatic inflammatory pseudotumour. ${ }^{107}$

Inflammatory pseudotumour of lymph node and spleen is a non-neoplastic entity distinct from IMT. Most affected patients are adults, and those with lymph node lesions frequently present with systemic symptoms and/or laboratory abnormalities similar to those seen in a minority of patients with IMT. ${ }^{108-111}$ Inflammatory pseudotumour of lymph node has a characteristic distribution, preferentially involving the connective tissue framework of the node (the capsule, trabeculae, and hilum) without forming a discrete mass, although in later stages, the lesion may efface the nodal architecture. ${ }^{110}$ Vascular changes, including perivascular fibrosis and vasculitis, are often seen within medium-sized vessels of the hilum or capsule, and extension into perinodal soft tissue is common. ${ }^{109-111}$ EBV has been detected in small lymphocytes in several cases of nodal inflammatory pseudotumour, but the spindle cells are EBV negative. ${ }^{37} 109$ In contrast to nodal lesions, splenic inflammatory pseudotumours are often asymptomatic, form a discrete mass, and usually lack 
associated vascular changes. ${ }^{39} 108109$ Furthermore, splenic lesions are rarely associated with nodal lesions and vice versa, suggesting that the two entities may be biologically unrelated, despite their histological similarities. ${ }^{108}$ Some investigators have detected EBV in the spindle cells of a subset of splenic inflammatory pseudotumours, ${ }^{37-39}$ whereas others reported no evidence of EBV infection. ${ }^{109}$ The spindle cells in some of the EBV-positive cases also expressed FDC markers, ${ }^{37}{ }^{39}$ and thus represent EBV-associated inflammatory pseudotumour-like FDC tumours, as discussed above. Inflammatory pseudotumours of lymph node and spleen are consistently negative for ALK. ${ }^{11} 39109$

The family of idiopathic fibrosclerosing lesions, including sclerosing mesenteritis, idiopathic retroperitoneal fibrosis, sclerosing mediastinitis, and orbital inflammatory pseudotumour, may also be considered within the umbrella of inflammatory pseudotumour. These lesions may occur synchronously or metachronously in the same patient. ${ }^{112}{ }^{113}$ Recently, an association with elevated serum IgG4 levels and other autoimmune disorders, particularly autoimmune pancreatitis, has been described in some patients with fibrosclerosing diseases, suggesting that a subset of these cases may be manifestations of the systemic IgG4-related sclerosing disease mentioned above in the discussion of pulmonary and hepatic inflammatory pseudotumours. ${ }^{96} 9714$ Grossly, the mass lesions formed by these processes are ill-defined and often encase adjacent structures, in contrast to the relatively circumscribed margins of IMT. Microscopically, the spindle cell component of fibrosclerosing lesions is usually significantly less cellular than that seen in even the most hypocellular IMTs, and the storiform, fascicular and myxoid/vascular patterns of IMT are absent. In addition, the inflammatory infiltrate is often patchy and perivascular, in contrast to the diffuse infiltrate seen in IMTs, and lymphocytic infiltration of blood vessel walls may be present in up to $50 \%$ of cases. $^{113} 115$

Finally, perhaps the most confusing topic in the recent literature on IMT is the distinction between pseudosarcomatous myofibroblastic proliferations (PMPs) and IMTs in the GU tract. Pseudosarcomatous spindle cell lesions in the GU tract have been described under a variety of names, including pseudosarcomatous fibromyxoid tumour, inflammatory pseudotumour, pseudosarcomatous myofibroblastic tumour/proliferation, pseudomalignant spindle cell proliferation, and postoperative spindle cell nodule for those arising following instrumentation. ${ }^{116-123}$ There are no histological differences between those that occur following trauma and those that arise spontaneously, the latter being more common. ${ }^{124} 125$ PMP usually occurs in adults, is not associated with systemic symptoms, and may recur locally in $10-20 \%$ of cases but does not metastasise. ${ }^{124} 125$ Although some authors do not distinguish between IMT and PMP in the GU tract, ${ }^{126} 127$ we and others ${ }^{42} 124125128$ believe that they are distinct entities that are separable on morphological grounds, and, in our experience, most fasciitis-like myofibroblastic lesions in the GU tract are PMPs. Histologically, PMPs are composed of a haphazard to loose fascicular arrangement of spindle cells, many of which have elongated bipolar cytoplasmic processes that are often brightly eosinophilic, mimicking rhabdomyoblasts. ${ }^{120} 121124$ The stroma is typically oedematous to myxoid with prominent vascularity and a variably dense acute and/or chronic inflammatory infiltrate. ${ }^{124} 125$ PMP may show focally more cellular fascicular areas, particularly in the deeper portion of the lesion away from the mucosal surface, but the storiform and hypocellular fibrous patterns of IMT are rarely seen. In addition, the inflammatory infiltrate of PMP is generally less dense than

\section{Take-home messages}

- The unqualified designation "inflammatory pseudotumour" is best avoided.

- Inflammatory myofibroblastic tumour is a distinctive neoplasm of intermediate biological potential with a predilection for the abdominopelvic region and lung of children and young adults.

- Histological features in inflammatory myofibroblastic tumours do not correlate well with clinical behaviour.

- Chromosomal translocations leading to activation of the ALK tyrosine kinase (and overexpression of the ALK protein) can be detected in approximately $50 \%$ of IMTs, but are uncommon in older patients.

- Inflammatory myofibroblastic tumour is a diagnosis of exclusion in middle-aged or older adults, and in somatic soft tissue, and the presence of more than mild nuclear atypia argues against the diagnosis.

that seen in IMT and lacks a prominent plasma cell component. ${ }^{124}{ }^{125}$ As both IMT and PMP are myofibroblastic in nature, there is considerable immunohistochemical overlap between the two lesions. PMP expresses SMA in approximately $70 \%$ of cases, desmin in $35-60 \%$, keratin in $42-94 \%$, and may also be positive for ALK, although the molecular basis for this is unclear. ${ }^{124} 125$ One study documented ALK positivity in 10 of 21 PMPs, but found no evidence of $A L K$ gene rearrangement in the 6 ALK-positive cases examined by FISH. ${ }^{124}$ Another group similarly found ALK expression in nearly 50\% of PMPs (12 of 26) but also identified $A L K$ gene rearrangements in 4 of the 6 ALK-positive cases examined, raising the possibility that these lesions may be neoplastic. ${ }^{125}$ Alternatively, this study (and others) may have included a heterogeneous group of lesions, both PMPs and "true" IMTs. However, there are certainly rare examples of bona fide IMTs that arise in the region of the bladder. Although the aetiology of PMP (reactive or neoplastic) and its possible relationship to IMT remain controversial, we believe there is sufficient data with respect to differences in clinical behaviour to warrant their separation.

In summary, IMT is a distinctive myofibroblastic neoplasm that has a predilection for the lung, abdomen, and pelvis of children and young adults, shows a tendency for local recurrence, and shows a characteristic cytogenetic abnormality in approximately half of the cases. IMTs should be distinguished from the variety of neoplastic and reactive lesions included under the umbrella term "inflammatory pseudotumour". To avoid ambiguity, the latter designation is best avoided, with the exception of inflammatory pseudotumour of lymph node and spleen and orbital inflammatory pseudotumour, which are distinct clinicopathological entities. Finally, one should keep in mind that IMT is a diagnosis of exclusion in middle-aged or older adults, and in skin and somatic soft tissue, and the presence of nuclear hyperchromasia, atypical mitoses, or more than mild nuclear atypia argues strongly against the diagnosis.

Competing interests: None declared.

\section{REFERENCES}

1. Brunn H. Two interesting benign lung tumors of contradictory histopathology. J Thorac Surg 1939;9:119-31.

2. Umiker W0, Iverson L. Postinflammatory tumors of the lung; report of four cases simulating xanthoma, fibroma, or plasma cell tumor. J Thorac Surg 1954;28:55-63.

3. Tang TT, Segura AD, Oechler HW, et al. Inflammatory myofibrohistiocytic proliferation simulating sarcoma in children. Cancer 1990;65:1626-34. 
4. Wu JP, Yunis EJ, Fetterman G, et al. Inflammatory pseudo-tumours of the abdomen: plasma cell granulomas. J Clin Pathol 1973;26:943-8.

5. Scully RE, Mark EJ, McNeey BU. Case records of the Massachusetts General Hospital. Case 13-1984. N Engl J Med 1984:310:839-45.

6. Pisciotto PT, Gray GF Jr, Miller DR. Abdominal plasma cell pseudotumor. J Pediatr 1978;93:628-30.

7. Gonzalez-Crussi F, deMello DE, Sotelo-Avila C. Omental-mesenteric myxoid hamartomas. Infantile lesions simulating malignant tumors. Am J Surg Pathol 1983:7:567-78.

8. Day DL, Sane S, Dehner LP. Inflammatory pseudotumor of the mesentery and small intestine. Pediatr Radiol 1986;16:210-15.

9. Meis JM, Enzinger FM. Inflammatory fibrosarcoma of the mesentery and retroperitoneum. A tumor closely simulating inflammatory pseudotumor. Am J Surg Pathol 1991;15:1146-56

10. Coffin CM, Watterson J, Priest JR, et al. Extrapulmonary inflammatory myofibroblastic tumor (inflammatory pseudotumor). A clinicopathologic and immunohistochemical study of 84 cases. Am J Surg Pathol 1995;19:859-72.

11. Cook JR, Dehner LP, Collins MH, et al. Anaplastic lymphoma kinase (ALK) expression in the inflammatory myofibroblastic tumor: a comparative immunohistochemical study. Am J Surg Pathol 2001;25:1364-71.

12. Myint MA, Medeiros LJ, Sulaiman RA, et al. Inflammatory pseudotumor of the ileum. A report of a multifocal, transmural lesion with regional lymph node involvement. Arch Pathol Lab Med 1994;118:1138-42.

13. Wenig BM, Devaney K, Bisceglia M. Inflammatory myofibroblastic tumor of the larynx. A clinicopathologic study of eight cases simulating a malignant spindle cell neoplasm. Cancer 1995;76:2217-29.

14. Sciot R, Dal Cin P, Fletcher CD, et al. Inflammatory myofibroblastic tumor of bone: report of two cases with evidence of clonal chromosomal changes. Am J Surg Pathol 1997;21:1166-72.

15. Ramachandra S, Hollowood K, Bisceglia M, et al. Inflammatory pseudotumour of soft tissues: a clinicopathological and immunohistochemical analysis of 18 cases. Histopathology 1995;27:313-23.

16. Hausler M, Schaade L, Ramaekers VT, et al. Inflammatory pseudotumors of the central nervous system: report of 3 cases and a literature review. Hum Pathol 2003;34:253-62.

17. Rabban JT, Zaloudek CJ, Shekitka KM, et al. Inflammatory myofibroblastic tumor of the uterus: a clinicopathologic study of 6 cases emphasizing distinction from aggressive mesenchymal tumors. Am J Surg Pathol 2005;29:1348-55.

18. Janik JS, Janik JP, Lovell MA, et al. Recurrent inflammatory pseudotumors in children. J Pediatr Surg 2003;38:1491-5.

19. Pettinato G, Manivel JC, De Rosa N, et al. Inflammatory myofibroblastic tumor (plasma cell granuloma). Clinicopathologic study of 20 cases with immunohistochemical and ultrastructural observations. Am J Clin Pathol 1990;94:538-46.

20. Spencer H. The pulmonary plasma cell/histiocytoma complex. Histopathology 1984;8:903-16.

21. Souid AK, Ziemba MC, Dubansky AS, et al. Inflammatory myofibroblastic tumor in children. Cancer 1993;72:2042-8.

22. Yoshizaki K, Matsuda T, Nishimoto N, et al. Pathogenic significance of interleukin-6 (IL-6/BSF-2) in Castleman's disease. Blood 1989:74:1360-7.

23. Rohrlich P, Peuchmaur M, Cocci SN, et al. Interleukin-6 and interleukin-1 beta production in a pediatric plasma cell granuloma of the lung. Am J Surg Pathol 1995;19:590-5.

24. Azuno Y, Yaga K, Suehiro Y, et al. Inflammatory myoblastic tumor of the uterus and interleukin-6. Am J Obstet Gynecol 2003;189:890-1.

25. Gomez-Roman JJ, Ocejo-Vinyals G, Sanchez-Velasco P, et al. Presence of human herpesvirus-8 DNA sequences and overexpression of human IL-6 and cyclin D1 in inflammatory myofibroblastic tumor (inflammatory pseudotumor). Lab Invest 2000;80:1121-6.

26. Vujanic GM, Berry PJ, Frank JD. Inflammatory pseudotumor of the kidney with extensive metaplastic bone. Pediatr Pathol 1992;12:557-61.

27. Hussong JW, Brown M, Perkins SL, et al. Comparison of DNA ploidy, histologic, and immunohistochemical findings with clinical outcome in inflammatory myofibroblastic tumors. Mod Pathol 1999:12:279-86.

28. Coffin CM, Hornick JL, Fletcher CD. Inflammatory myofibroblastic tumor: comparison of clinicopathologic, histologic, and immunohistochemical features including ALK expression in atypical and aggressive cases. Am J Surg Pathol 2007;31:509-20.

29. Warter A, Satge D, Roeslin N. Angioinvasive plasma cell granulomas of the lung Cancer 1987:59:435-43.

30. Yamamoto $\mathbf{H}, 0$ da $Y$, Saito $T$, et al. p53 Mutation and MDM2 amplification in inflammatory myofibroblastic tumours. Histopathology 2003:42:431-9.

31. Donner LR, Trompler RA, White RRt. Progression of inflammatory myofibroblastic tumor (inflammatory pseudotumor) of soft tissue into sarcoma after several recurrences. Hum Pathol 1996;27:1095-8.

32. Biselli R, Ferlini C, Fattorossi A, et al. Inflammatory myofibroblastic tumor (inflammatory pseudotumor): DNA flow cytometric analysis of nine pediatric cases. Cancer 1996;77:778-84

33. Meis-Kindblom JM, Kjellstrom C, Kindblom LG. Inflammatory fibrosarcoma: update, reappraisal, and perspective on its place in the spectrum of inflammatory myofibroblastic tumors. Semin Diagn Pathol 1998;15:133-43.

34. Coffin CM, Fletcher JA. Inflammatory myofibroblastic tumor. In: Fletcher CDM, Unni KK, Mertens F, eds. World Health Organization classification of tumours.
Pathology and genetics of tumours of soft tissue and bone. Lyon: IARC Press, 2002:91-3.

35. Remotti F, Fetsch JF, Miettinen M. Keratin 1 expression in endothelia and mesenchymal tumors: an immunohistochemical analysis of normal and neoplastic tissues. Hum Pathol 2001;32:873-9.

36. Tamas EF, Epstein Jl. Detection of residual tumor cells in bladder biopsy specimens: pitfalls in the interpretation of cytokeratin stains. Am J Surg Pathol 2007;31:390-7.

37. Arber DA, Kamel OW, van de Rijn M, et al. Frequent presence of the Epstein-Barr virus in inflammatory pseudotumor. Hum Pathol 1995:26:1093-8.

38. Lewis JT, Gaffney RL, Casey MB, et al. Inflammatory pseudotumor of the spleen associated with a clonal Epstein-Barr virus genome. Case report and review of the literature. Am J Clin Pathol 2003;120:56-61.

39. Neuhauser TS, Derringer GA, Thompson LD, et al. Splenic inflammatory myofibroblastic tumor (inflammatory pseudotumor): a clinicopathologic and immunophenotypic study of 12 cases. Arch Pathol Lab Med 2001;125:379-85.

40. Mergan F, Jaubert F, Sauvat F, et al. Inflammatory myofibroblastic tumor in children: clinical review with anaplastic lymphoma kinase, Epstein-Barr virus, and human herpesvirus 8 detection analysis. J Pediatr Surg 2005:40:1581-6.

41. Yamamoto H, Kohashi K, Oda Y, et al. Absence of human herpesvirus-8 and Epstein-Barr virus in inflammatory myofibroblastic tumor with anaplastic large cell lymphoma kinase fusion gene. Pathol Int 2006;56:584-90.

42. Sukov WR, Cheville JC, Carlson AW, et al. Utility of ALK-1 protein expression and ALK rearrangements in distinguishing inflammatory myofibroblastic tumor from malignant spindle cell lesions of the urinary bladder. Mod Pathol 2007;20:592-603.

43. Gomez-Roman JJ, Sanchez-Velasco P, Ocejo-Vinyals G, et al. Human herpesvirus8 genes are expressed in pulmonary inflammatory myofibroblastic tumor (inflammatory pseudotumor). Am J Surg Pathol 2001:25:624-9.

44. Coffin CM, Patel A, Perkins S, et al. ALK1 and p80 expression and chromosomal rearrangements involving 2p23 in inflammatory myofibroblastic tumor. Mod Pathol 2001;14:569-76.

45. Griffin CA, Hawkins AL, Dvorak C, et al. Recurrent involvement of $2 p 23$ in inflammatory myofibroblastic tumors. Cancer Res 1999;59:2776-80

46. Pulford K, Lamant L, Morris SW, et al. Detection of anaplastic lymphoma kinase (ALK) and nucleolar protein nucleophosmin (NPM)-ALK proteins in normal and neoplastic cells with the monoclonal antibody ALK1. Blood 1997;89:1394-404.

47. Medeiros LJ, Elenitoba-Johnson KS. Anaplastic large cell lymphoma. Am J Clin Pathol 2007;127:707-22.

48. Cools J, Wlodarska I, Somers R, et al. Identification of novel fusion partners of ALK the anaplastic lymphoma kinase, in anaplastic large-cell lymphoma and inflammatory myofibroblastic tumor. Genes Chromosomes Cancer 2002;34:354-62.

49. Bridge JA, Kanamori M, Ma Z, et al. Fusion of the ALK gene to the clathrin heavy chain gene, CLTC, in inflammatory myofibroblastic tumor. Am J Pathol 2001;159:411-5

50. Lawrence B, Perez-Atayde A, Hibbard MK, et al. TPM3-ALK and TPM4-ALK oncogenes in inflammatory myofibroblastic tumors. Am J Pathol 2000;157:377-84.

51. Debelenko LV, Arthur DC, Pack SD, et al. Identification of CARS-ALK fusion in primary and metastatic lesions of an inflammatory myofibroblastic tumor. Lab Invest 2003;83:1255-65

52. Debiec-Rychter Marynen P, Hagemeijer A, et al. ALK-ATIC fusion in urinary bladder inflammatory myofibroblastic tumor. Genes Chromosomes Cancer 2003;38:187-90

53. Ma Z, Hill DA, Collins MH, et al. Fusion of ALK to the Ran-binding protein 2 (RANBP2) gene in inflammatory myofibroblastic tumor. Genes Chromosomes Cancer 2003:37:98-105

54. Panagopoulos I, Nilsson T, Domanski HA, et al. Fusion of the SEC31L1 and ALK genes in an inflammatory myofibroblastic tumor. Int J Cancer 2006;118:1181-6.

55. Trinei M, Lanfrancone $L$, Campo $E$, et al. A new variant anaplastic lymphoma kinase (ALK)-fusion protein (ATIC-ALK) in a case of ALK-positive anaplastic large cell lymphoma. Cancer Res 2000;60:793-8.

56. Touriol C, Greenland C, Lamant L, et al. Further demonstration of the diversity of chromosomal changes involving 2p23 in ALK-positive lymphoma: 2 cases expressing ALK kinase fused to CLTCL (clathrin chain polypeptide-like). Blood 2000;95:3204-7.

57. Lamant L, Dastugue N, Pulford K, et al. A new fusion gene TPM3-ALK in anaplastic large cell lymphoma created by a $(1 ; 2)(q 25 ; p 23)$ translocation. Blood 1999;93:3088-95

58. Liang $\mathbf{X}$, Meech SJ, Odom LF, et al. Assessment of $t(2 ; 5)(p 23 ; q 35)$ translocation and variants in pediatric ALK+ anaplastic large cell lymphoma. Am J Clin Pathol 2004:121:496-506.

59. Meech SJ, McGavran L, Odom LF, et al. Unusual childhood extramedullary hematologic malignancy with natural killer cell properties that contains tropomyosin 4-anaplastic lymphoma kinase gene fusion. Blood 2001;98:1209-16.

60. Chan JK, Cheuk W, Shimizu M. Anaplastic lymphoma kinase expression in inflammatory pseudotumors. Am J Surg Pathol 2001;25:761-8.

61. Li X0, Hisaoka M, Shi DR, et al. Expression of anaplastic lymphoma kinase in sof tissue tumors: an immunohistochemical and molecular study of 249 cases. Hum Pathol 2004:35:711-21.

62. Nascimento AF, Ruiz R, Hornick JL, et al. Calcifying fibrous 'pseudotumor': clinicopathologic study of 15 cases and analysis of its relationship to inflammatory myofibroblastic tumor. Int J Surg Pathol 2002:10:189-96.

63. Cessna MH, Zhou H, Sanger WG, et al. Expression of ALK1 and p80 in inflammatory myofibroblastic tumor and its mesenchymal mimics: a study of 135 cases. Mod Pathol 2002:15:931-8. 
64. Cerfolio RJ, Allen MS, Nascimento AG, et al. Inflammatory pseudotumors of the lung. Ann Thorac Surg 1999;67:933-6.

65. Karnak I, Senocak ME, Ciftci A0, et al. Inflammatory myofibroblastic tumor in children: diagnosis and treatment. J Pediatr Surg 2001;36:908-12.

66. Kovach SJ, Fischer AC, Katzman PJ, et al. Inflammatory myofibroblastic tumors J Surg Oncol 2006;94:385-91.

67. Melloni G, Carretta A, Ciriaco P, et al. Inflammatory pseudotumor of the lung in adults. Ann Thorac Surg 2005; 79:426-32.

68. Malhotra V, Tatke M, Malik R, et al. An unusual case of plasma cell granuloma involving lung and brain. Indian J Cancer 1991;28:223-7.

69. Hasegawa SL, Schofield DE, Fletcher CD. Inflammatory myofibroblastic tumor or inflammatory fibrosarcoma? Pathol Case Rev 1998;3:128-34.

70. Hagenstad CT, Kilpatrick SE, Pettenati MJ, et al. Inflammatory myofibroblastic tumor with bone marrow involvement. A case report and review of the literature. Arch Pathol Lab Med 2003;127:865-7.

71. Trojan A, Stallmach T, Kollias $\mathrm{S}$, et al. Inflammatory myofibroblastic tumor with CNS involvement. Onkologie 2001;24:368-72.

72. Watanabe K, Tajino T, Sekiguchi M, et al. Inflammatory myofibroblastic tumor (inflammatory fibrosarcoma) of the bone. Arch Pathol Lab Med 2000;124:1514-7.

73. Petridis AK, Hempelmann RG, Hugo HH, et al. Metastatic low-grade inflammatory myofibroblastic tumor (IMT) in the central nervous system of a 29-year-old male patient. Clin Neuropathol 2004;23:158-66.

74. Morotti RA, Legman MD, Kerkar N, et al. Pediatric inflammatory myofibroblastic tumor with late metastasis to the lung: case report and review of the literature. Pediatr Dev Pathol 2005;8:224-9.

75. Chun YS, Wang L, Nascimento AG, et al. Pediatric inflammatory myofibroblastic tumor: anaplastic lymphoma kinase (ALK) expression and prognosis. Pediatr Blood Cancer 2005;45:796-801.

76. Biselli R, Boldrini R, Ferlini C, et al. Myofibroblastic tumours: neoplasias with divergent behaviour. Ultrastructural and flow cytometric analysis. Pathol Res Pract 1999;195:619-32

77. Winfield HL, Rosenberg AS, Antonescu CR, et al. Monophasic sarcomatoid carcinoma of the scalp: a case mimicking inflammatory myofibroblastic tumor and a review of cutaneous spindle cell tumors with myofibroblastic differentiation. J Cutan Pathol 2003;30:393-400.

78. Ritter JH, Humphrey PA, Wick MR. Malignant neoplasms capable of simulating inflammatory (myofibroblastic) pseudotumors and tumefactive fibroinflammatory lesions: pseudopseudotumors. Semin Diagn Pathol 1998;15:111-32.

79. Wick MR, Ritter JH, Nappi 0 . Inflammatory sarcomatoid carcinoma of the lung: report of three cases and clinicopathologic comparison with inflammatory pseudotumors in adult patients. Hum Pathol 1995;26:1014-21.

80. Henricks WH, Chu YC, Goldblum JR, et al. Dedifferentiated liposarcoma: a clinicopathological analysis of 155 cases with a proposal for an expanded definition of dedifferentiation. Am J Surg Pathol 1997;21:271-81.

81. McCormick D, Mentzel T, Beham A, et al. Dedifferentiated liposarcoma. Clinicopathologic analysis of 32 cases suggesting a better prognostic subgroup among pleomorphic sarcomas. Am J Surg Pathol 1994;18:1213-23.

82. Coindre JM, Hostein I, Maire G, et al. Inflammatory malignant fibrous histiocytomas and dedifferentiated liposarcomas: histological review, genomic profile, and MDM2 and CDK4 status favour a single entity. J Pathol 2004;203:82230.

83. Binh MB, Sastre-Garau X, Guillou L, et al. MDM2 and CDK4 immunostainings are useful adjuncts in diagnosing well-differentiated and dedifferentiated liposarcoma subtypes: a comparative analysis of 559 soft tissue neoplasms with genetic data. Am J Surg Pathol 2005;29:1340-7.

84. Miettinen M, Sobin LH, Sarlomo-Rikala M. Immunohistochemical spectrum of GISTs at different sites and their differential diagnosis with a reference to CD117 (KIT). Mod Pathol 2000;13:1134-42

85. Andriko JW, Kaldjian EP, Tsokos M, et al. Reticulum cell neoplasms of lymph nodes: a clinicopathologic study of 11 cases with recognition of a new subtype derived from fibroblastic reticular cells. Am J Surg Pathol 1998;22:1048-58.

86. Chan AC, Serrano-Olmo J, Erlandson RA, et al. Cytokeratin-positive malignant tumors with reticulum cell morphology: a subtype of fibroblastic reticulum cell neoplasm? Am J Surg Pathol 2000;24:107-16.

87. Nonaka D, Birbe R, Rosai J. So-called inflammatory myofibroblastic tumour: a proliferative lesion of fibroblastic reticulum cells? Histopathology 2005;46:604-13.

88. Merchant W, Calonje E, Fletcher CD. Inflammatory leiomyosarcoma: a morphological subgroup within the heterogeneous family of so-called inflammatory malignant fibrous histiocytoma. Histopathology 1995;27:525-32.

89. $\mathbf{~ N g ~ T L , ~ G o w n ~ A M , ~ B a r r y ~ T S , ~ e t ~ a l . ~ N u c l e a r ~ b e t a - c a t e n i n ~ i n ~ m e s e n c h y m a l ~ t u m o r s . ~}$ Mod Pathol 2005;18:68-74.

90. Van Dorpe J, Ectors N, Geboes K, et al. Is calcifying fibrous pseudotumor a late sclerosing stage of inflammatory myofibroblastic tumor? Am J Surg Pathol 1999;23:329-35.

91. Hill KA, Gonzalez-Crussi F, Chou PM. Calcifying fibrous pseudotumor versus inflammatory myofibroblastic tumor: a histological and immunohistochemical comparison. Mod Pathol 2001;14:784-90.

92. Matsubara 0, Tan-Liu NS, Kenney RM, et al. Inflammatory pseudotumors of the lung: progression from organizing pneumonia to fibrous histiocytoma or to plasma cell granuloma in 32 cases. Hum Pathol 1988;19:807-14.

93. Park SH, Choe GY, Kim CW, et al. Inflammatory pseudotumor of the lung in a child with mycoplasma pneumonia. J Korean Med Sci 1990;5:213-23.
94. Hartman GE, Shochat SJ. Primary pulmonary neoplasms of childhood: a review. Ann Thorac Surg 1983;36:108-19.

95. Zen Y, Kitagawa S, Minato H, et al. IgG4-positive plasma cells in inflammatory pseudotumor (plasma cell granuloma) of the lung. Hum Pathol 2005; 36:710-7.

96. Kamisawa T, Funata N, Hayashi Y, et al. A new clinicopathological entity of lgG4related autoimmune disease. J Gastroenterol 2003;38:982-4.

97. Kamisawa T, Okamoto A. Autoimmune pancreatitis: proposal of IgG4-related sclerosing disease. J Gastroenterol 2006:41:613-25.

98. Yousem SA, Tazelaar HD, Manabe T, et al. Inflammatory myofibroblastic tumor. In: Travis WD, Brambilla E, Muller-Hermelink HK, Harris C, eds. World Health Organization classification of tumours. Pathology and genetics of tumours of the lung, pleura, thymus, and heart. Lyon: IARC Press, 2004:105-6.

99. Bahadori M, Liebow AA. Plasma cell granulomas of the lung. Cancer 1973:31:191-208.

100. Anthony PP. Inflammatory pseudotumour (plasma cell granuloma) of lung, liver and other organs. Histopathology 1993;23:501-3.

101. Lupovitch A, Chen R, Mishra S. Inflammatory pseudotumor of the liver. Report of the fine needle aspiration cytologic findings in a case initially misdiagnosed as malignant. Acta Cytol 1989;33:259-62.

102. Malatjalian DA, Morris J, Bodurtha A. Isolation of Klebsiella pneumoniae from an hepatic inflammatory pseudotumor. Can J Gastroenterol 1992;6:84-6.

103. Selves $\mathbf{J}$, Meggetto $\mathbf{F}$, Brousset $\mathrm{P}$, et al. Inflammatory pseudotumor of the liver. Evidence for follicular dendritic reticulum cell proliferation associated with clonal Epstein-Barr virus. Am J Surg Pathol 1996;20:747-53.

104. Shek TW, Ho FC, Ng IO, et al. Follicular dendritic cell tumor of the liver. Evidence for an Epstein-Barr virus-related clonal proliferation of follicular dendritic cells. Am J Surg Pathol 1996;20:313-24.

105. Cheuk W, Chan JK, Shek TW, et al. Inflammatory pseudotumor-like follicular dendritic cell tumor: a distinctive low-grade malignant intra-abdominal neoplasm with consistent Epstein-Barr virus association. Am J Surg Pathol 2001:25:721-31.

106. Zen Y, Harada K, Sasaki M, et al. IgG4-related sclerosing cholangitis with and without hepatic inflammatory pseudotumor, and sclerosing pancreatitis-associated sclerosing cholangitis: do they belong to a spectrum of sclerosing pancreatitis? Am J Surg Pathol 2004;28:1193-203.

107. Zen Y, Fujji T, Sato Y, et al. Pathological classification of hepatic inflammatory pseudotumor with respect to lgG4-related disease. Mod Pathol 2007;20:884-94.

108. Davis RE, Warnke RA, Dorfman RF. Inflammatory pseudotumor of lymph nodes. Additional observations and evidence for an inflammatory etiology. Am J Surg Pathol 1991;15:744-56

109. Kutok JL, Pinkus GS, Dorfman DM, et al. Inflammatory pseudotumor of lymph node and spleen: an entity biologically distinct from inflammatory myofibroblastic tumor. Hum Pathol 2001;32:1382-7.

110. Moran CA, Suster S, Abbondanzo SL. Inflammatory pseudotumor of lymph nodes: a study of 25 cases with emphasis on morphological heterogeneity. Hum Pathol 1997;28:332-8.

111. Perrone T, De Wolf-Peeters C, Frizzera G. Inflammatory pseudotumor of lymph nodes. A distinctive pattern of nodal reaction. Am J Surg Pathol 1988;12:351-61.

112. Comings DE, Skubi KB, Van Eyes J, et al. Familial multifocal fibrosclerosis. Findings suggesting that retroperitoneal fibrosis, mediastinal fibrosis, sclerosing cholangitis, Riedel's thyroiditis, and pseudotumor of the orbit may be different manifestations of a single disease. Ann Intern Med 1967;66:884-92.

113. Dehner LP, Coffin CM. Idiopathic fibrosclerotic disorders and other inflammatory pseudotumors. Semin Diagn Pathol 1998;15:161-73.

114. Zen Y, Sawazaki A, Miyayama S, et al. A case of retroperitoneal and mediastinal fibrosis exhibiting elevated levels of lgG4 in the absence of sclerosing pancreatitis (autoimmune pancreatitis). Hum Pathol 2006;37:239-43.

115. Corradi D, Maestri R, Palmisano A, et al. Idiopathic retroperitoneal fibrosis: clinicopathologic features and differential diagnosis. Kidney Int 2007;72:742-53.

116. Roth JA. Reactive pseudosarcomatous response in urinary bladder. Urology 1980;16:635-7.

117. Proppe KH, Scully RE, Rosai J. Postoperative spindle cell nodules of genitourinary tract resembling sarcomas. A report of eight cases. Am J Surg Pathol 1984;8:1018.

118. Nochomovitz LE, Orenstein JM. Inflammatory pseudotumor of the urinary bladder-possible relationship to nodular fasciitis. Two case reports, cytologic observations, and ultrastructural observations. Am J Surg Pathol 1985;9:366-73.

119. Ro JY, Ayala AG, Ordonez NG, et al. Pseudosarcomatous fibromyxoid tumor of the urinary bladder. Am J Clin Pathol 1986;86:583-90.

120. Albores-Saavedra J, Manivel JC, Essenfeld H, et al. Pseudosarcomatous myofibroblastic proliferations in the urinary bladder of children. Cancer 1990;66:1234-41.

121. Jones EC, Clement PB, Young RH. Inflammatory pseudotumor of the urinary bladder. A clinicopathological, immunohistochemical, ultrastructural, and flow cytometric study of 13 cases. Am J Surg Pathol 1993;17:264-74.

122. Lundgren $\mathbf{L}$, Aldenborg $\mathrm{F}$, Angervall $\mathrm{L}$, et al. Pseudomalignant spindle cell proliferations of the urinary bladder. Hum Pathol 1994;25:181-91.

123. Hojo $\mathbf{H}$, Newton WA Jr, Hamoudi AB, et al. Pseudosarcomatous myofibroblastic tumor of the urinary bladder in children: a study of 11 cases with review of the literature. An Intergroup Rhabdomyosarcoma Study. Am J Surg Pathol 1995:19:1224-36. 
124. Hirsch MS, Dal Cin P, Fletcher CD. ALK expression in pseudosarcomatous myofibroblastic proliferations of the genitourinary tract. Histopathology 2006;48:569-78.

125. Harik LR, Merino C, Coindre JM, et al. Pseudosarcomatous myofibroblastic proliferations of the bladder: a clinicopathologic study of 42 cases. Am J Surg Pathol 2006;30:787-94.

126. Freeman A, Geddes N, Munson P, et al. Anaplastic lymphoma kinase (ALK 1) staining and molecular analysis in inflammatory myofibroblastic tumours of the bladder: a preliminary clinicopathological study of nine cases and review of the literature. Mod Pathol 2004;17:765-71.

127. Tsuzuki T, Magi-Galluzzi C, Epstein JI. ALK-1 expression in inflammatory myofibroblastic tumor of the urinary bladder. Am J Surg Pathol 2004:28:1609-14.

128. Weiss SW. Pseudosarcomatous myofibroblastic proliferations of the bladder: a clinicopathologic study of 42 cases (in reply). Am J Surg Pathol 2007:31:642.

\section{BMJ Careers online re-launches}

BMJ Careers online has re-launched to give you an even better online experience. You'll still find our online services such as jobs, courses and careers advice, but now they're even easier to navigate and quicker to find.

New features include:

- Job alerts - you tell us how often you want to hear from us with either daily or weekly alerts

- Refined keyword searching making it easier to find exactly what you want

- Contextual display - when you search for articles or courses we'll automatically display job adverts relevant to your search

- Recruiter logos linked directly to their organisation homepage - find out more about the company before you apply

- RSS feeds now even easier to set up

Visit careers.bmj.com to find out more. 